\title{
CONSIDERAÇÕES SOBRE O QUADRO DA AIDS NA BAHIA
}

\author{
Inês Dourado', Ceci Vilar Noronha', Andrea Maria Barbosa², Renata Lago²
}

O Brasil encontra-se com 103.262 casos acumulados de AIDS até março de 1997. A transmissão heterossexual parece estar aumentando no país, diminuindo a razăo de homens/mulheres infectados. O Nordeste, caracterizado pela pobreza da sua populaçăo, é uma regiăo vulnerável a essa epidemia: as carências educacionais que conformam a realidade local intensificam o risco de transmissăo pelo HIV. Na Bahia, pode-se verificar que a AIDS e a infecção pelo HIV vêm se propagando rapidamente nos últimos anos, apesar da subnotificação e subdiagnóstico de casos. O presente estudo pretende apresentar o quadro epidemiológico de AIDS na Bahia e detalhar a assistência à populaçăo infectada pelo HIV, com base nos dados de uma unidade de atendimento ambulatorial. A situação epidemiológica estudada e o potencial de expansão desse quadro não parecem estar devidamente contemplados pelas açðes de assistência em curso. As responsabilidades do setor público de saúde definidas na legislação estadual, particularmente no que se refere à dimensão dos riscos de doenças, năo estão sendo implementadas em toda a sua extensão.

Palavras chaves: AIDS; epidemiologia; infecção; HIV; prevenção.

\section{Introdução}

O Brasil encontra-se com 103.262 casos acumulados de AIDS de janeiro de 1980 a março de 1997, correspondendo a uma incidência acumulada de 74,0/100.000 habitantes(1). Do total de casos notificados ao Ministério da Saúde, a metade $(53 \%)$ está associada a alguma forma de contato sexual, sendo que $34 \%$ (do total de casos) sáo devidos a interaçóes sexuais entre homens (homo $e$ bissexual) e $19 \%$ entre homens e mulheres. A transmissão por uso de drogas endovenosas corresponde a $20,7 \%$; por transfusão sangüínea em geral, a $2,4 \%$ e para os hemofilicos, a $0,9 \%$. A transmissão perinatal corresponde a $2,4 \% \mathrm{e}$ a por causas não definidas, a $19,9 \%^{1}$.

Visto a distribuiçáo dos casos de AIDS no Brasil, pretendemos com este estudo sistematizar os dados relativos à situação epidemiológica do HIV/AIDS na Bahia e

\footnotetext{
${ }^{1}$ Instituto de Saúde Coletiva/UFBA.

${ }^{2}$ Estudantes de medicina da UFBA, bolsistas do Programa Integrado de Bolsas de Iniciação Científica (PIBIC). Instituto de Saúde Coletiva/UFBA, Rua Padre Feijó, 29/4º andar, Canela, Salvador - Bahia, 40.110.170. Tel.: 071-245-0544 FAX: 071-237-5856, email: maines@ufba.br
}

(1)Essa taxa de incidência não representa uma taxa média de doença, mas uma taxa para um período de 15 anos (1982-1996). Essa medida é uma aproximaçáo da taxa de incidência acumulada que é calculada para uma coorte fixa com uma população de risco no denominador no início do período de seguimento. 
detalhar a assistência à população infectada pelo HIV, tendo como base a unidade de atendimento ambulatorial do Hospital Universitário Professor Edgar Santos (HUPES), que pertence à Universidade Federal da Bahia (UFBA).

\section{O quadro epidemiológico na Bahia}

De acordo com o banco de dados do Ministério da Saúde, pode-se descrever a Bahia, em comparação com os outros estados brasileiros, como tendo o status de risco intermediário - não tão alto quanto São Paulo e Rio de Janeiro, porém mais atingida que outras áreas do Nordeste e do Centro-Oeste. No entanto, o quadro epidemiológico de DST/ AIDS na Bahia vem sendo pouco analisado no nível local. de informação em saúde no Brasil e particularmente no Nordeste.

A Bahia encontra-se com 2.308 casos de AIDS até março de 1997 (Figura 2), correspondendo a uma incidência acumulada de 20,9 por 100.000 habitantes $^{1}$. A maioria desses casos são de indivíduos jovens, do sexo masculino, com comportamento homo e/ou bissexual e usuários de drogas injetáveis. A distribuição por faixa etária evidencia o predomínio de indivíduos em idade economicamente produtiva (20 a 39 anos) ${ }^{2}$.

As figuras $3 \mathrm{a}$ (homens) e $3 \mathrm{~b}$ (mulheres) apresentam as tendências relativas dos modos de transmissáo da epidemia. $\mathrm{Na}$ figura $3 \mathrm{a}$, observa-se que, quanto à transmissão relacionada às práticas sexuais dos casos do sexo masculino, importantes modificaçóes

Figura 1: Taxa de incidência de AIDS (x $10^{5}$ habitantes) segundo ano de diagnóstico. Bahia 1984-1996

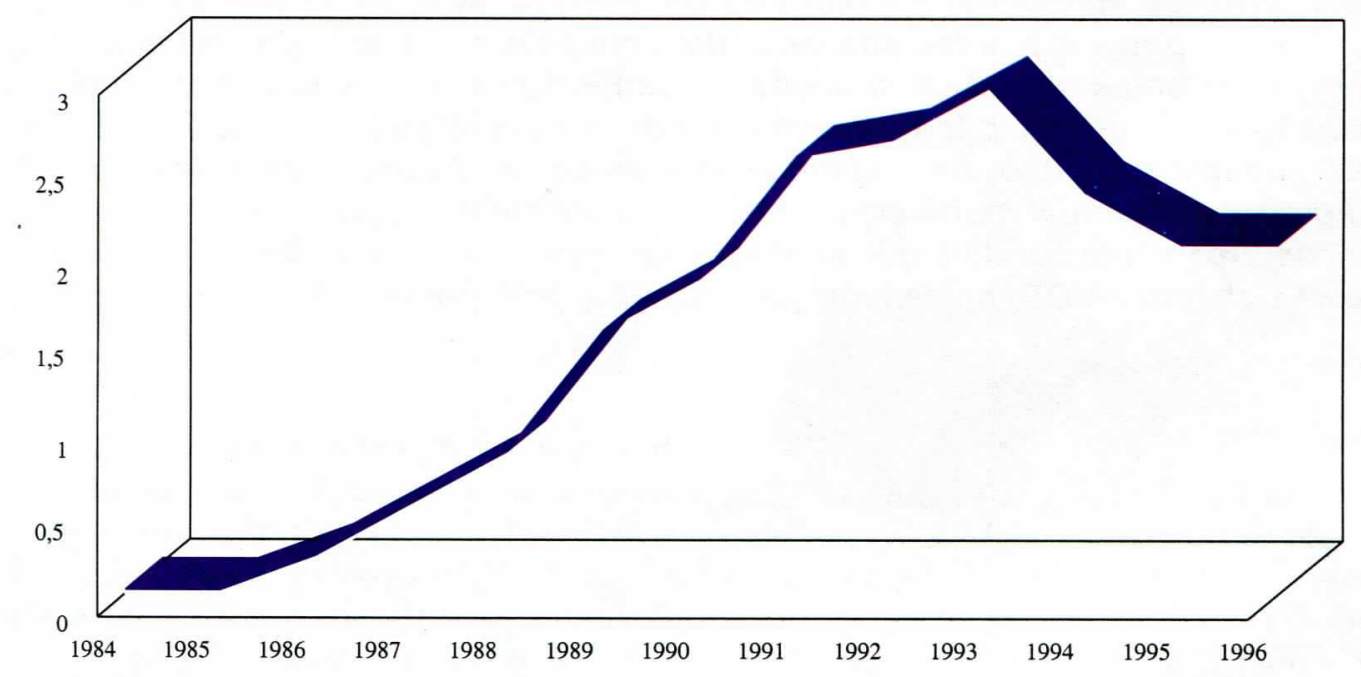

Fonts: Aids Boletim Epidemiológico, 1997.

O primeiro caso de AIDS na Bahia foi identificado em 1984. Em termos de análise da progressão da epidemia, a Figura 1 demonstra um crescimento das taxas de incidência, com a taxa mais elevada em 1993 $\left(2,9 \times 10^{5}\right) . \mathrm{Na}$ fase seguinte, em 1994, nota-se um declínio, voltando a elevar-se em 1996. O declínio observado pode ser atribuído à subnotificação e/ou ao subregistro de casos, ante às reconhecidas deficiências nos sistemas ocorreram desde o início da epidemia, equivalentes ao que foi observado em outras regiões do país. Nas fases iniciais da epidemia, a maioria dos casos referia-se a práticas de tipo exclusivamente homossexual ou bissexual. Durante o período estudado, observa-se uma clara tendência à diminuição da proporção de casos com práticas do tipo homo e bissexual, simultaneamente a um aumento da freqüência relativa de casos com prática heterossexual. 
Figura 2: Casos notificados de AIDS segundo o ano de diagnóstico. Bahia, 1984-1996

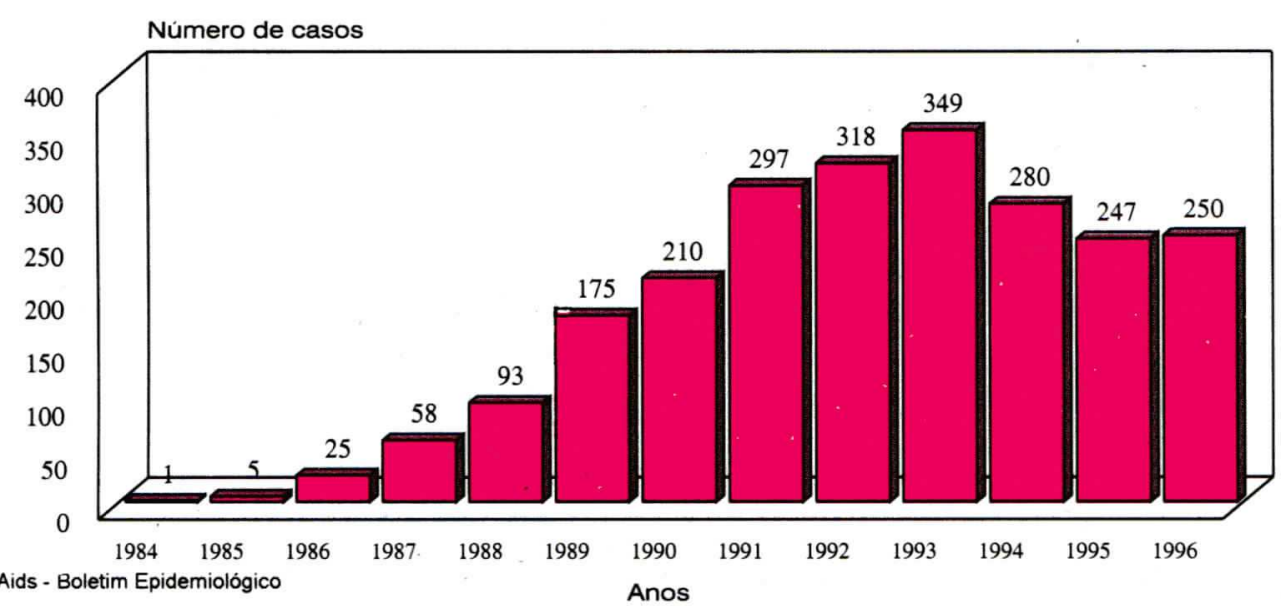

Figura 3: Proporção de casos de AIDS em homens e mulheres segundo categoria de exposição e ano de diagnóstico. Bahia, 1984-1996

(a) homens

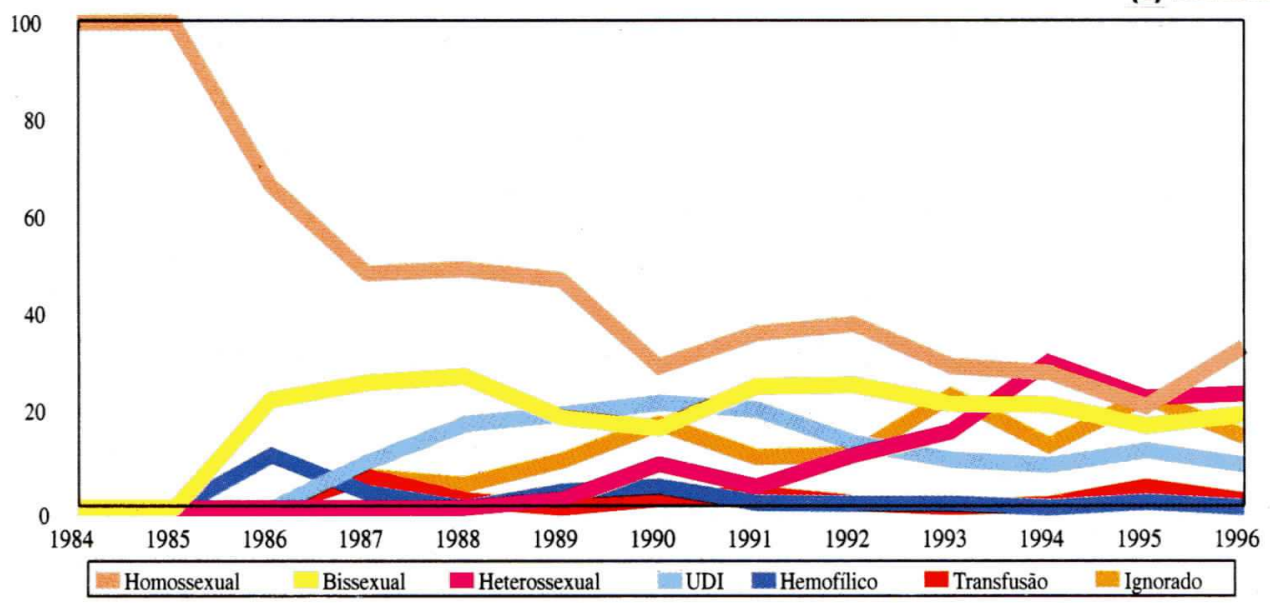

(b) mulheres

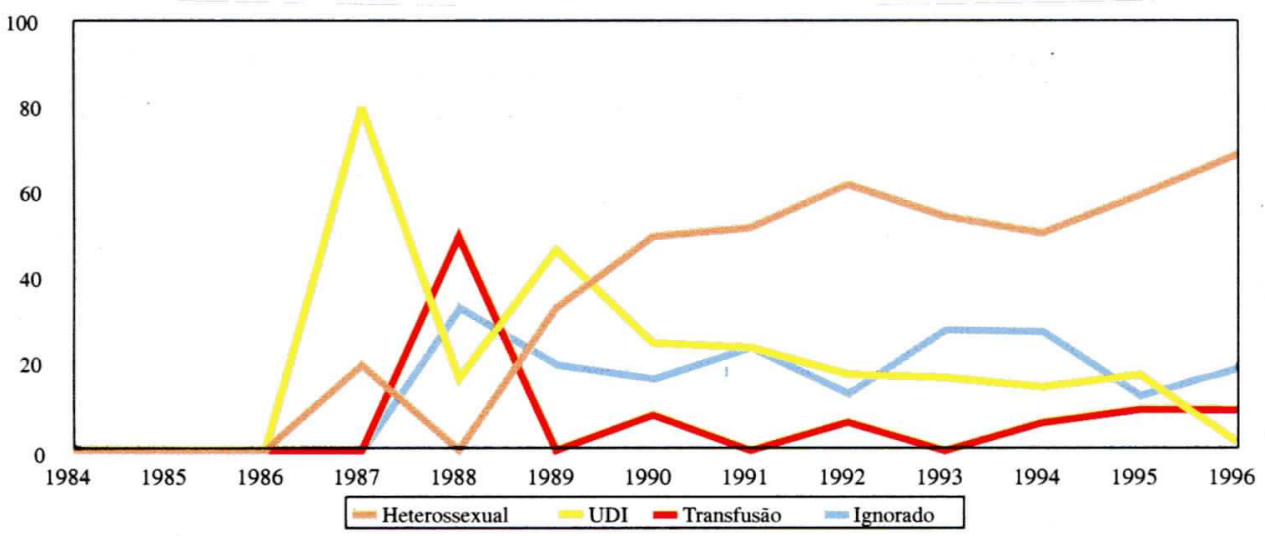


Disso resulta que, a partir de 1994, a transmissão por meio de práticas heterossexuais (30\%) atinge uma proporção comparada às práticas homossexuais $(30,3 \%)$ e bissexuais (24\%). A transmissão por drogas (UDI) tem a sua participação aumentada de 1986 até 1991, reduzindo-se, aparentemente, a partir de 1992, de acordo com os casos notificados. Finalmente, cabe destacar a curiosa evolução da proporção de casos sem referência ao tipo de transmissão que, na primeira metade do período analisado, variava em torno de $15 \%$, reduzindo-se gradualmente a partir daí, voltando à proporção inicial em $1990 \mathrm{e}$ aumentando para valores em torno de $30 \%$ a partir de 1995. Com relação às mulheres, o que mais chama a atenção é a crescente transmissão através de relações heterossexuais para o total de casos, caindo a participação relativa das drogas e das transfusôes nos casos ocorridos nos últimos anos da série (Figura $3 b)$.
A distribuição dos casos por Diretorias Regionais de Saúde (DIRES) evidencia um maior percentual de ocorrência na $1^{\underline{a}}$ DIRES, composta pela Região Metropolitana de Salvador, com maior concentraçáo de casos na capital. A I 1 - DIRES apresentou uma incidência acumulada de 81,7 casos/100.000 hab., registrados entre 1984 e março de 1997, correspondendo a um total de 1.533 casos. Essa incidência é maior que no Estado da Bahia $(20,9 / 100.000$ hab. $)$ e que na região Nordeste $(20,9 / 100.000 \text { hab. })^{1}$. Outras DIRES com o coeficiente de incidência acima de 4,5 casos/ 100.000 hab. são: Itabuna, Juazeiro, Jequié, Feira de Santana, Eunápolis e Vitória da Conquista (Mapa 1).

Em Salvador, nota-se que o maior coeficiente de incidência é no Distrito Sanitário do Centro Histórico (55,3/100.000 hab.). Essa área concentra indivíduos com comportamentos de risco para a infecção pelo HIV, como profissionais do sexo, usuários de drogas

Mapa 1: Incidência cumulativa de AIDS segundo Diretorias Regionais de Saúde do Estado da Bahia, 1984-1994

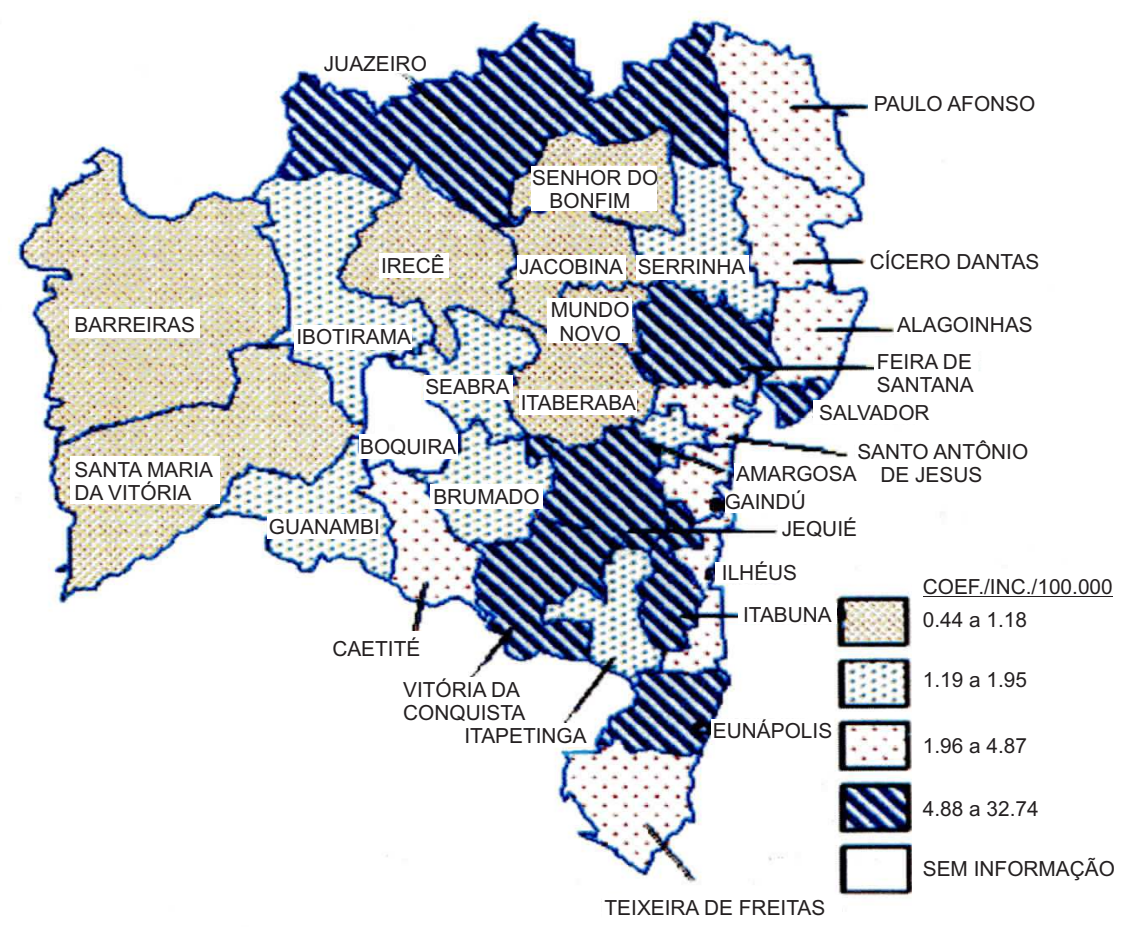


e meninos de rua (Mapa 2).

A distribuição dos casos de AIDS por faixa etária e categoria de transmissão em Salvador segue a mesma tendência do Estado da Bahia (SESAB, 1994, dados não publicados).

Estudos de soroprevalência do HIV têm sido utilizados para se conhecer a magnitude da epidemia em diferentes grupos populacionais. Na Bahia, um estudo feito entre 1988-1990, com diferentes grupos de indivíduos, demonstrou altas proporçōes de infectados entre os chamados "grupos de risco" (40,2\% entre homo/bissexuais masculinos, $38,4 \%$ entre usuários de drogas injetáveis (UDI) e $13,3 \%$ entre profissionais do sexo) ${ }^{3}$. Outro estudo, com 170 UDI que moram ou freqüentam o Centro Histórico de Salvador, estimou a ocorrência de infecção pelo HIV em $49 \%{ }^{4}$.

O projeto nacional de vigilância sentinela, definido como "Inquéritos
Sorológicos Conduzidos em Populaçôes Selecionadas em Momentos Diferentes", foi implantado em 1992 pelo Programa Nacional de DST/AIDS do Ministério da Saúde. O inquérito realizado em Salvador naquele ano, em uma clínica de DST, demonstrou uma soroprevalência de $9,4 \%$ para o $\mathrm{HIV}^{5}$. O Centro de Orientação e Apoio Sorológico (COAS) da Secretaria Estadual de Saúde registrou, no seu atendimento, uma soropositividade de $7 \%$ para os homens e de $5,4 \%$ para as mulheres, de outubro de 94 a julho de 1995 (COAS, 1995, dados não publicados). Vale ressaltar que os percentuais do COAS se referem a um grupo de pessoas que procuram esse serviço de testagem anônima voluntariamente, a partir da sua própria percepção de riscos.

Esses estudos demonstram que a epidemia de HIV/AIDS em Salvador não é pouco expressiva, apresentando prevalências altas entre grupos com práticas de risco para a

Mapa 2: Coeficiente de incidência de AIDS por Distrito de residência, Salvador, 1994

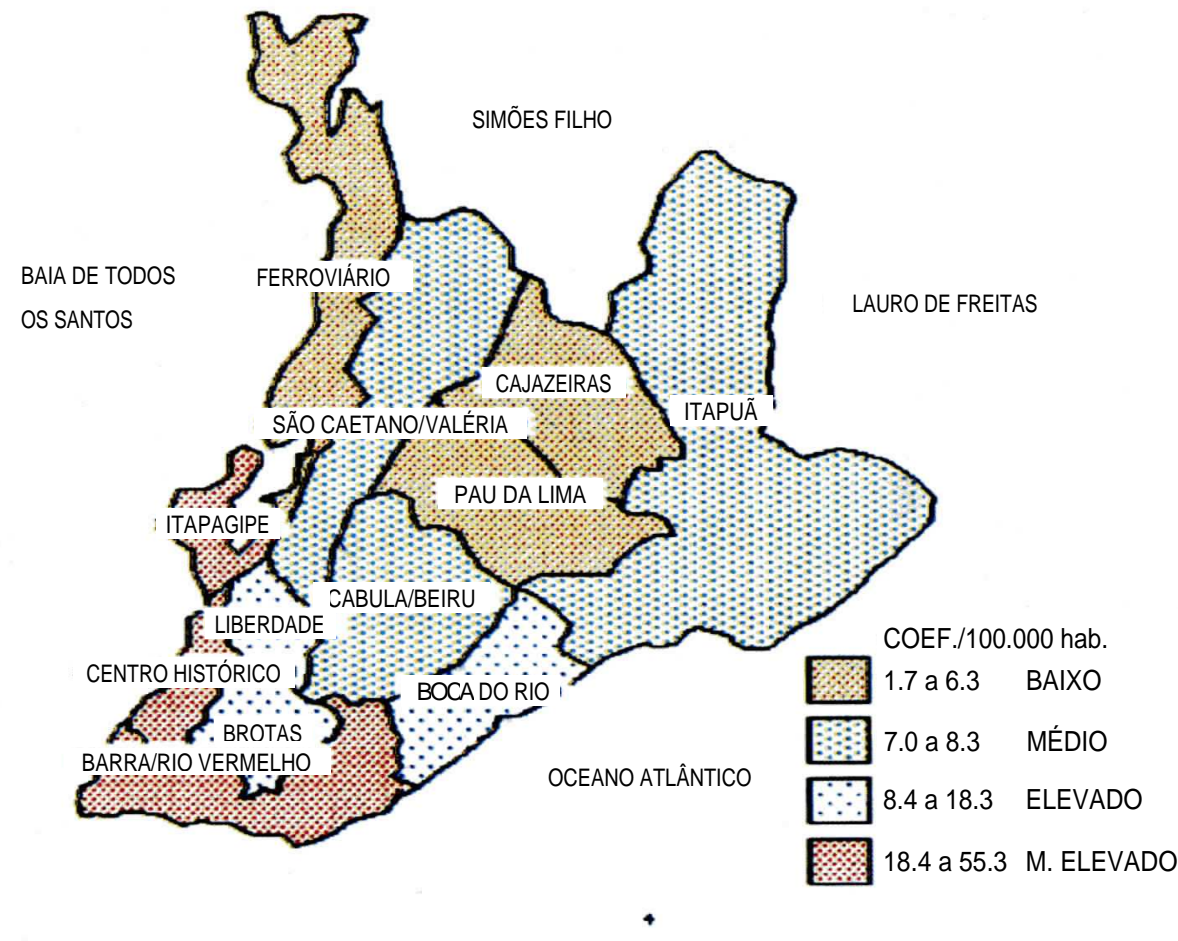


infecção e com potencial de expandir a transmissão para outros grupos populacionais.

Em relação a outras doenças sexualmente transmissíveis (DST), em 1992 foram notificados em Salvador 1.874 casos. O condiloma acuminato apresenta o maior coeficiente de incidência $(29,15 / 100.000$ hab.), seguindo-se, em ordem de magnitude, a gonorréia $(19,36 / 100.000$ hab.) e a sífilis $(18,35 / 100.000$ hab. $)$. Outras DST apresentaram uma menor incidência; dentre essas, o linfogranuloma venéreo, o cancro mole e a oftalmia gonocócica (SESAB, 1993, dados não publicados). Para as quatro DST de maior incidência em 1992 observa-se um predomínio na faixa etária de 30-39 anos, sendo os homens acometidos mais freqüientemente de gonorréia e uretrite não-gonocócica e as mulheres, de condiloma e sífilis. Sabe-se que não só a sífilis, mas outras DST que cursam com lesôes ulcerosas mucocutâneas, favorecem a transmissão do HIV. Medidas preventivas para pacientes com DST são extremamente necessárias para uma maior prevenção da infecção pelo HIV.

A propagação do HIV no Nordeste, caracterizado pela pauperização econômica da sua população, coloca tal região numa situação de grande vulnerabilidade a essa epidemia, pois a carência de educação e de serviços públicos especializados $\mathrm{em}$ atender o infectado pelo HIV que conforma a realidade local intensifica a gravidade da epidemia da AIDS.

Os países em desenvolvimento, cujos serviços de saúde são muitas vezes insuficientes para atender às necessidades da maioria da população, revelam ser os mais afetados pela epidemia de HIV/AIDS. A AIDS, além de competir com outras enfermidades pelos escassos recursos econômicos do Sistema Único de Saúde, concorre para a diminuição das defesas do organismo humano, aumentando, assim, o impacto de outras doenças de caráter endêmico, como a tuberculose. A infecção pelo HIV vem contribuindo para o chamado "recrudescimento" da tuberculose no Brasil e no mundo ${ }^{\circ}$.

\section{Perfil dos infectados pelo HIV na Unidade Docente Assistencial em Infectologia}

Realizou-se um estudo do atendimento dos pacientes infectados pelo HIV no ambulatório da Unidade Docente Assistencial em Infectologia (UDAI) do HUPES/UFBA, de 1989 a 1991.

Utilizou-se um formulário específico para a transcrição dos dados contidos nos prontuários médicos dos pacientes que tiveram sua primeira consulta no período acima referido. Estudantes do $3^{\circ}$ e do $4^{\circ}$ ano de medicina realizaram a coleta dos dados entre os meses de outubro de 1994 a março de 1995. Tentando verificar a evoluçáo das queixas e diagnósticos dos pacientes, foram coletadas informaçôes relativas à $\mathrm{l}^{\mathbf{a}}$ consulta $\mathrm{e}$ à consulta mais recente até 3 de dezembro de 1994.

No período de 1989 a 1991, 211 pacientes foram atendidos na UDAI. Estão inclúdos nesse estudo $73 \%$ (154) dos casos, todos com confirmação sorológica para a infecção pelo HIV.

Dos 154 pacientes soropositivos incluídos nessa análise, $19,5 \%$ (30) foram atendidos em 1989, 40,9\% (63) em $1990 \mathrm{e}$ $39 ; 6 \%(61) \mathrm{em} \mathrm{1991.} \mathrm{Esse} \mathrm{aumento} \mathrm{no}$ percentual de atendimento de 1989 a 1990 deve-se à expansão e/ou à procura do atendimento da UDAI, serviço estruturado em 1988. Nos dados epidemiológicos para o Estado da Bahia observa-se que, de $175 \mathrm{em}$ 1989, o número de casos aumentou para 297 $(69,7 \%) \mathrm{em} 1991$ (Figura 2).

Em termos de idade, a faixa etária mais atingida foi a de 31 a 40 anos $(70,8 \%)$. A média de idade para os homens foi a de 32 anos e para as mulheres, 27. Essa média manteve-se praticamente a mesma em cada um dos anos estudados. Dos 154 pacientes, $84,4 \%$ era do sexo masculino. A maioria era de cor negra $(63,2 \%)$, com predominância de trabalhadores do Setor de Serviços e Transportes (39,8\%). Em geral, exerciam ocupação de baixa qualificação e remuneração (Tabela 1 ). 
Tabela 1: Características dos pacientes infectados pelo HIV atendidos na Unidade Docente Assistencial em Infectologia (UDAI), Hospital Universitário Professor Edgar Santos, 1989-91.

\begin{tabular}{|c|c|c|}
\hline Variáveis & $\mathbf{N}^{\mathbf{0}}$ & $\%$ \\
\hline \multicolumn{3}{|l|}{ Idade } \\
\hline $0-15$ & 3 & 1,9 \\
\hline $16-30$ & 33 & 21,4 \\
\hline $31-40$ & 109 & 70,8 \\
\hline $41-70$ & 9 & 5,8 \\
\hline total & 154 & 100,0 \\
\hline \multicolumn{3}{|l|}{ Sexo } \\
\hline masculino & 130 & 84,4 \\
\hline feminino & 24 & 15,6 \\
\hline total & 154 & 100,0 \\
\hline \multicolumn{3}{|l|}{ Cor } \\
\hline negro & 91 & 63,2 \\
\hline branco & 53 & 36,8 \\
\hline total & 144 & 100,0 \\
\hline \multicolumn{3}{|l|}{ Ocupação } \\
\hline serviços e transportes & 53 & 39,8 \\
\hline atividades do comércio & 26 & 19,5 \\
\hline outros & 54 & 40,6 \\
\hline total & 133 & 100,0 \\
\hline \multicolumn{3}{|l|}{ Procedência } \\
\hline Salvador & 121 & 39,8 \\
\hline outras cidades & 18 & 12,7 \\
\hline outros estados & 3 & 2,1 \\
\hline total & 142 & 100,0 \\
\hline \multicolumn{3}{|c|}{$\begin{array}{l}\text { Atendimento anterior a UDAI } \\
\text { utilizado pelos pacientes }\end{array}$} \\
\hline $\operatorname{sim}$ & 106 & 82,8 \\
\hline não & 22 & 17,2 \\
\hline total & 128 & 100,0 \\
\hline \multicolumn{3}{|c|}{$\begin{array}{l}\text { Serviços anteriores a UDAI utilizado } \\
\text { pelos pacientes }\end{array}$} \\
\hline HUPES* & 23 & 33,3 \\
\hline HCRS** & 14 & 20,3 \\
\hline outros & 32 & 46,4 \\
\hline total & 69 & 100,0 \\
\hline
\end{tabular}

A diferença para o total de 154 deve-se aos ignorados para a variável em questão.

* Hospital Universitário Professor Edgar Santos

** Hospital Central Roberto Santos 
A UDAI atendeu a $85,2 \%$ de pacientes residentes em Salvador, e houve $14,8 \%$ de atendimentos para indivíduos de outras cidades da Bahia ou procedentes de outros estados (Tabela 1). Entre os pacientes atendidos no Hospital Universitário Professor Edgar Santos (HUPES), há alguns provenientes de municípios tais como: Alagoinhas, Feira de Santana, Itabuna, Conceição do Almeida, Cruz das Almas e Jequié. Além desses locais, há outros mais próximos, pertencentes à Região Metropolitana de Salvador. A presença de pacientes que se deslocam por mais de $100 \mathrm{~km}$ atesta a má distribuição do atendimento na extensão territorial do Estado. Itabuna localiza-se a $222 \mathrm{~km}$ e Jequié a $195 \mathrm{~km}$ de distância de Salvador. Ambas as cidades pertencem a outras Diretorias Regionais de Saúde.

Os pacientes de Salvador são moradores de uma ampla faixa territorial que compreende desde o Subúrbio Ferroviário até Itapoá, no outro extremo litorâneo, passando por bairros históricos centrais.

Ainda na tabela 1 , observa-se que um percentual expressivo de pacientes $(82,8 \%)$ tiveram um atendimento anterior ao da UDAI: $33,3 \%$ foi encaminhado por outros serviços do próprio HUPES, 20,3\% do Hospital Central Roberto Santos, que atende a pacientes com
HIV/AIDS, e 46,4\%, de outros serviços.

$O$ padrão de transmissão encontrado nos prontuários demonstra que as relaçōes sexuais parecem ser a via predominante tanto para homens $(64,8 \%)$ quanto para mulheres $(70 \%)$. A possível transmissão endovenosa foi de $15 \%$ para os homens e $10 \%$ para as mulheres. Para ambos os sexos foi igual a $20 \%$ a transmissão por duas categorias de exposição, sexual e sangüínea (uso de drogas injetáveis e/ou transfusão) (Tabela 2). Foram registrados 3 casos de transmissão vertical e dois casos de pacientes hemofílicos, ambos do sexo masculino e diagnosticados em 1990.

Em relação aos comportamentos de risco, $56,3 \%$ dos homens relataram homossexualidade; $24 \%$, bissexualidade e $17,7 \%$, heterossexualidade. A totalidade das mulheres referiu ser heterossexual, sendo que duas mulheres declararam-se profissionais do sexo. Os homens mais freqüentemente relataram ter tido outras DST do que as mulheres $(18,5 \%$ e $4,2 \%$, respectivamente). Dentre as DST, 33 prontuários apresentaram o teste para sífilis (VDRL) positivo, sendo mais freqüente entre os homens $(22,3 \%)$ do que entre as mulheres $(16,7 \%)$ (Tabela 2$)$.

O consumo de algum tipo de droga foi relatado por $45,4 \%$ dos pacientes $\mathrm{e}$, desses, $16,9 \%$ referiram uso de drogas endovenosas.

Tabela 2: Categoria de exposição, comportamento sexual e DST segundo o sexo. Unidade Docente Assistencial em Infectologia, Hospital Universitário Professor Edgar Santos, 1989-91.

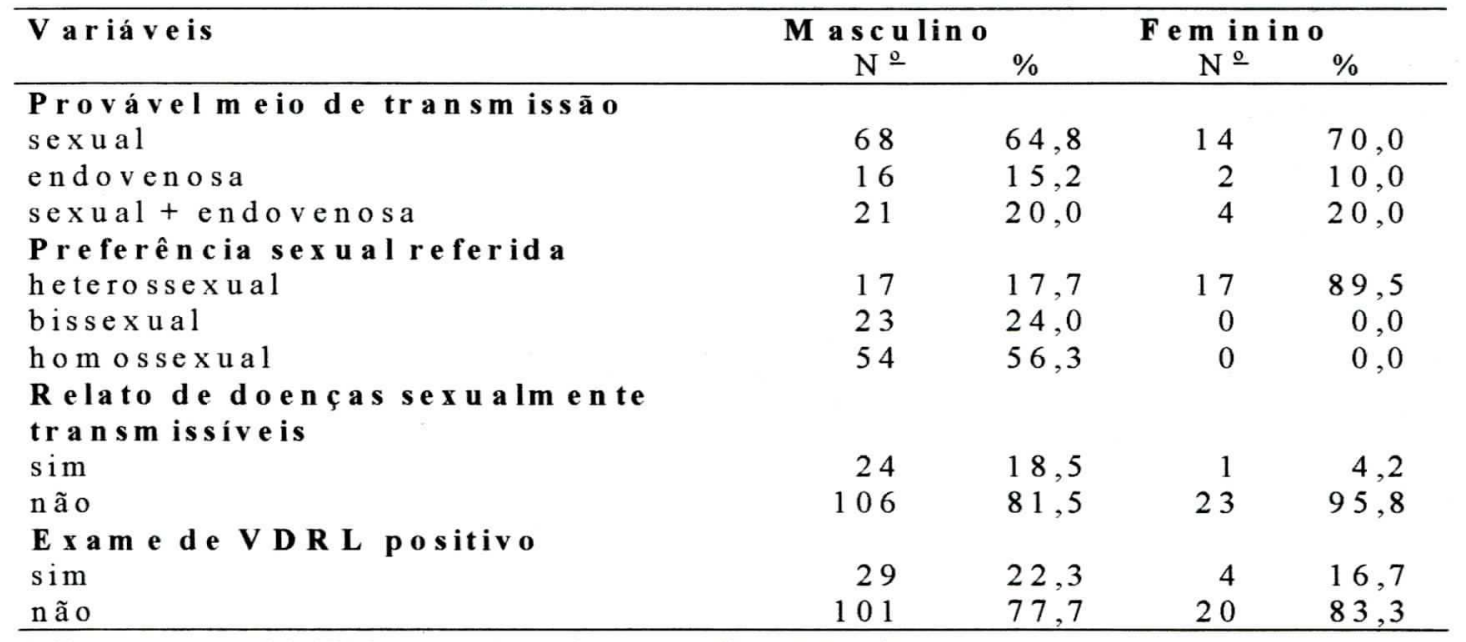

A diferença para o total de 154 deve-se aos ignorados para a variável em questão. 
Figura 4: Percentual de pacientes que já tinham conhecimento anterior do status de soropositivo

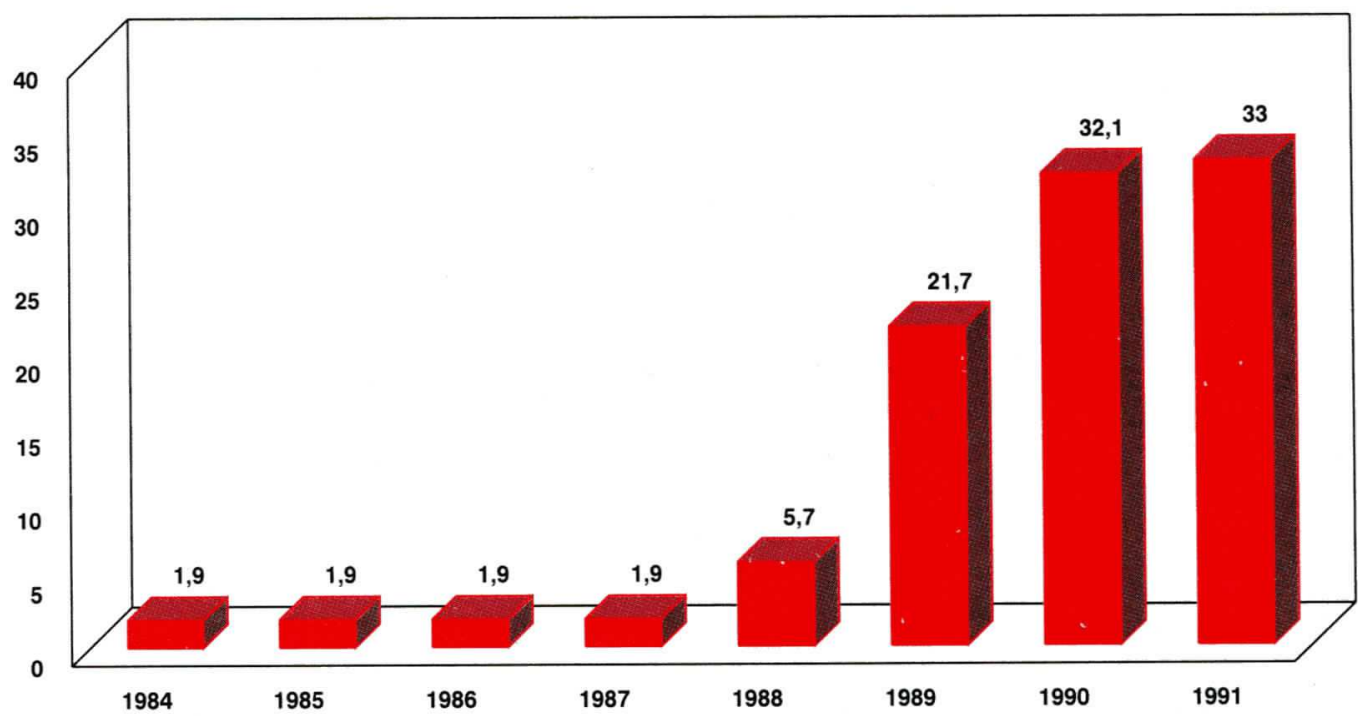

No nível nacional, o percentual de casos de AIDS atribuídos ao uso de drogas injetáveis é de $20 \%$.

No grupo de pacientes do sexo masculino, recuperou-se alguns fragmentos de relatos de vida que são indicativos da presença de mais de um meio de transmissão provável. As histórias de infecção no grupo feminino sugerem uma maior frequiência da transmissão entre casais heterossexuais.

Observou-se ainda nos prontuários que o sofrimento psíquico ocasionado com a descoberta da infecção pelo HIV acarreta um tipo de assistência especial, a exemplo dos pacientes que apresentaram depressão ou outro tipo de transtorno comportamental, requerendo assistência psiquiátrica. Assim, os cuidados com os soropositivos devem ser planejados de modo a prover as necessidades de acompanhamento psicológico. Esse aspecto distingue os pacientes de AIDS dos demais, uma vez que o diagnóstico representa uma modificação significativa ou limitaçôes para toda a vida, passando, inclusive, a conviver com os preconceitos sociais e uma expectativa de morte próxima.

$\mathrm{O}$ conhecimento do status de soropositivo por parte dos pacientes era pouco expressivo até 1987 (1,9\%), aumentando a cada ano a partir de 1988. Essa evolução demonstra o crescimento da epidemia de HIV/ AIDS na Bahia (Figura 4).

Em relação ao quadro clínico, as queixas mais freqüentes referidas em ambas as consultas foram de diarréia, perda de peso, febre, gânglios aumentados e tosse (Tabela 3).

Quanto ao diagnóstico registrado no prontuário, em ambas as consultas os achados mais freqüentes foram: candidíase, tuberculose, parasitoses, diarréia crônica e toxoplasmose (Tabela 4). Esses achados aproximam-se dos dados registrados a nível nacional ${ }^{1}$.

$\mathrm{Na}$ tentativa de avaliar a evolução da infecção, procurou-se obter resultados de parâmetros imunológicos nos registros médicos, tais como a contagem de subpopulaçōes de linfócitos CD4+e CD8+. Observou-se pouca solicitação desses parâmetros no atendimento clínico. No entanto, a freqüência da realização dos mesmos aumentou ao longo dos três anos da investigação. A freqüência do uso do AZT também não pôde ser devidamente avaliada, por essa informação não constar de forma adequada nos prontuários. 
Tabela 3 : Queixas apresentadas por 154 pacientes na primeira e na última consulta. Unidade Docente Assistencial em Infectologia, Hospital Universitário Professor Edgar Santos, 1989-91.

\begin{tabular}{lcclrr}
\hline $\begin{array}{l}\text { Queixas da } \\
\text { la Consulta }\end{array}$ & No & $\%$ & $\begin{array}{l}\text { Queixas da } \\
\text { Úlima Consulta }\end{array}$ & No & $\%$ \\
\hline Diarréia & 53 & 34,4 & Febre & 33 & 23,7 \\
Perda de peso & 49 & 31,8 & Tosse & 30 & 21,6 \\
Febre & 42 & 27,3 & Diarréia & 25 & 18,0 \\
Linfadenopatia & 37 & 24,0 & Lesões de pele & 17 & 12,2 \\
Tosse & 32 & 20,8 & A stenia & 16 & 11,5 \\
Lesões de pele & 25 & 16,2 & Perdade peso & 15 & 10,8 \\
Astenia & 19 & 12,3 & Inapetência & 14 & 10,1 \\
Dorabdominal & 16 & 10,4 & Dor abdominal & 10 & 7,2 \\
Inapetência & 14 & 9,1 & Vias respiratórias & 10 & 7,2 \\
Cefaléia & 12 & 7,8 & Linfoadenopatia & 9 & 6,5 \\
Dortorácica & 8 & 5,2 & Disfagia & 9 & 6,5 \\
Disfagia & 8 & 5,2 & Cefaléia & 8 & 5,8 \\
\hline
\end{tabular}

Tabela 4 : Diagnóstico apresentado por 154 pacientes na primeira e na última consulta. Unidade Docente Assistencial em Infectologia, Hospital Universitário Professor Edgar Santos, 1989-91.

\begin{tabular}{|c|c|c|c|c|c|}
\hline $\begin{array}{l}\text { Diagnóstico } \\
1 \underline{\text { a C Consulta }}\end{array}$ & № & $\%$ & $\begin{array}{l}\text { Diagnóstico } \\
\text { Última Consulta }\end{array}$ & $\mathrm{N}^{\circ}$ & $\%$ \\
\hline Candidíase & 31 & 20,1 & C andidíase & 29 & 20,9 \\
\hline Parasitoses & 19 & 12,3 & Tuberculose & 10 & 7,2 \\
\hline Tuberculose & 11 & 7,1 & Infecção respiratória & 10 & 7,2 \\
\hline Diarréia crônica & 11 & 7,1 & Diarréia crônica & 9 & 6,5 \\
\hline Toxoplasmose & 9 & 5,8 & Parasitoses & 7 & 5,0 \\
\hline Infecção respiratória & 5 & 3,2 & Sarcoma de Kaposi & 5 & 3,6 \\
\hline Infecção urinária & 4 & 2,6 & Toxoplasmose & 5 & 3,6 \\
\hline Sifilis & 4 & 2,6 & Anemia & 4 & 2,9 \\
\hline $\mathrm{PCP}$ & 3 & 1,9 & $\mathrm{PCP}$ & 3 & 2,2 \\
\hline
\end{tabular}

\section{Discussão}

Os estudos sobre AIDS no Brasil vêm enfatizando algumas tendências como: a interiorização da epidemia, saindo das grandes cidades para atingir outros locais de menor densidade urbana; a rápida propagação da infecção no segmento feminino da população, diminuindo sistematicamente os diferenciais homens/mulheres infectados; o aumento da mortalidade por tuberculose como um problema diretamente associado à AIDS, o incremento da transmissão heterossexual, perinatal e por uso de drogas endovenosas, além dos desafios aos serviços de saúde para conter a propagação do $\mathrm{HIV}$, via ações promocionais e educativas ${ }^{7,8,9,10,11}$.

A Bahia segue a tendência descrita para o País. A interiorização da transmissão do HIV no Estado atinge não apenas a Região Metropolitana de Salvador, mas regióes situadas ao norte, oeste e sul do Estado (Mapa 1). Os indivíduos jovens, principalmente do grupo etário de 30-39 anos, distinguiram-se como os mais vulneráveis à infecção. A razão homem/mulher encontra-se em torno de 4:1. $\mathrm{O}$ aumento do número de casos na população feminina aponta para uma necessidade de intensificação das açốes de prevenção no nível dos serviços de pré-natal, ginecologia e de atividades de educação em saúde.

O padrão de transmissão encontrado entre os pacientes da UDAI é de natureza complexa, dado envolver diferentes categorias de exposição: homossexual, heterossexual, endovenosa e vertical. A existência desse 
complexo padrão requer uma maior atenção quanto às medidas de prevençáo e controle. Vale ressaltar a importância das açóes educativas, como é consenso entre os pesquisadores, visando à mudança de padróes de comportamento de risco para a infecção pelo HIV.

No momento, na ausência de uma prevenção para a infecção baseada na tecnologia médica (vacina), as campanhas educativas/ informativas, a capacitação de pessoal e a melhoria da assistência à saúde assumem um papel central para conter a propagação do HIV. A atividade de prevenção do HIV/AIDS não se deve restringir ao setor saúde, mas incluir diferentes campos disciplinares como a educação, as ciências sociais e a comunicaçáo envolvendo as instituiçōes governamentais e não-governamentais atuando de forma integrada.

Paim propóe, para reduzir a morbidade e mortalidade na população, a construção de um modelo assistencial que se distancie do atendimento à demanda espontânea, mediante campanhas e programas especiais (de caráter vertical), tal como descrito para a $\mathrm{AIDS}^{13}$. A nova proposta assistencial deve ser direcionada à concretização da vigilância à saúde, redefinindo o escopo da Vigilância Sanitária e Epidemiológica para atingir níveis diferenciados de controle de riscos e de danos - tanto aqueles que se situam no momento atual quanto no futuro. Considera o autor que os riscos também são problemas de saúde ${ }^{12}$.

No caso específico da AIDS, em que os riscos são provenientes do modo de vida dos indivíduos - incluindo escolhas no plano do exercício da sexualidade - a preocupação com o controle dos riscos ante à exposiçáo deve envolver, necessariamente, uma cuidadosa identificação dos contatos sexuais entre um indivíduo soropositivo e seus/suas parceiros(as). A vigilância epidemiológica deveria ter um papel fundamental em realizar açóes educativas e testes anti-HIV em relação a uma determinada rede de contatos sociais, agindo de modo antecipado com relação aos danos. Ademais, considerando a escassez de recursos tecnológicos para deter o curso dos sintomas e danos, uma ênfase maior deve ser atriburída ao controle dos riscos.

A condição de agravamento da pobreza da populaçáo no país, evidenciado pelos indicadores de desemprego e concentração de renda, atinge particularmente o Nordeste e relaciona-se ao quadro preocupante de expansão da AIDS e da inadequação da assistência.

Altman ressalta em seu livro a possível existência de duas epidemias de AIDS na década de 90: "a dos países ricos e ados países pobres"13. Nos países desenvolvidos, os avanços terapêuticos e a disponibilidade de tratamentos que aumentam cada vez mais a sobrevida dos pacientes pode levar a epidemia de HIV/AIDS a uma condição estável. Entretanto, essa possível situação de estabilidade da infecção está longe de ser pensada para os países em desenvolvimento, nos quais as precárias condições de vida da maioria da população dificultam o acesso à educação, aos meios de prevenção da infecção - ainda que existentes e ao tratamento adequado da infecçáo e/ou doença. "Talvez o desenvolvimento de uma vacina barata, eficiente tanto para prevenir quanto como terapia, altere a situação. Mas é difícil escapar à realidade de que o HIV/AIDS irá se tornar, cada vez mais, outra arena onde se reproduzem as já existentes dimensóes de desigualdade".

Scheper-Hughes, analisando criticamente a situação da AIDS no Brasil, também chama a atenção para a gravidade da situação das populações pobres, que já são, cotidianamente, estigmatizadas como marginais e negligenciadas com relação à assistência à saúde ${ }^{14}$.

\section{Agradecimentos}

As autoras agradecem a colaboração dos profissionais da UDAI e dos técnicos do arquivo médico do Hospital Professor Edgar Santos pelo uso dos prontuários. Aos técnicos da Divisão de Vigilância Epidemiológica da Secretaria de Saúde do Estado dá Bahia, pelo 
fornecimento dos dados da epidemia de AIDS. Ao Professor Jairnilson Paim também se agradece a revisāo e contribuiçóes ao texto.

\section{Bibliografia}

1. AIDS, Boletim Epidemiológico. Brasília: Ministério da Saúde, vol. 9, nº 5, 1997.

2. SESAB. Boletim Epidemiológico; 5:1-4, 1992.

3. Santos, I., J., dos; Couto- Fernandez, J.C.; Santana, A.J. Prevalence of HIV-1 antibodies in selected groups of a Brazilian city with African sociodemographic characteristics. Journal of Acquired Immune Deficiency Syndrome. 4:448-9, 1991.

4. Dourado I.; Andrade. T.; Montes, J.C.; Azevedo, C..; Galvão Castro, B. Infecção pelo HTLV em usuários de drogas injetáveis (UDI) na cidade de Salvador, Bahia: maior frequiência de HTLV-1. In: Seminário internacional sobre o uso e o abuso de drogas. Resumos.... Salvador: CETAD/ UFBA, 1995.

5. AIDS, Boletim Epidemiológico. Brasília: Ministério da Saúde, vol.7, no 8, 1994.

6. Castro, K. G. \& McMacken, M. La tuberculosis $y$ el virus de la inmunodeficiencia humana en los Estados Unidos, 1985-1992. Revista Argentina del Torax. 55(2): 169- 174, 1994.

7. Bastos, F. I.; Telles P.R.; Castilho E.; Barcellos, C. A epidemia da AIDS no Brasil. In: Minayo M.C.S. (org.). Os muitos Brasis: saúde e população na década de 80. Sáo Paulo-Rio de Janeiro:
Hucitec-ABRASCO, 1995

8. Campos, S. S. L. Situação da AIDS no Ceará, 1983-1991. In: Congresso Brasileiro de Epidemiologia, 2. Resumos ... BeloHorizonte-MG, 1992.

9. Guimarães, M. D. C. Epidemiologia da AIDS/HIV no Brasil. In: Lima, M.F., Costa, R.P. de S (org). Qualidade de Vida: compromisso da epidemiologia. Belo Horizonte: COOPMED/ABRASCO, pp 45-52, 1994.

10.Passos, S. R. C.; Lima, L. A.; Souza, E. \& Saraceni, V. Fatores de risco para infecção pelo HIV na clientela de um centro de testagem anônima. In: Congresso Brasileiro, 3., Congresso Ibero-Americano, 2., Congresso Latino-Americano de Epidemiologia,1. Resumos... Salvador: ABRASCO, 1995.

11.Sanches, K.R.B. Dez anos de epidemia da AIDS em mulheres no Rio de Janeiro. In: In: Congre'sso Brasileiro, 3., Congresso Ibero-Americano, 2., Congresso LatinoAmericano de Epidemiologia, 1, 1995. Resumos... Salvador: ABRASCO, 1995.

12.Paim, J. A reforma sanitária e os modelos assistenciais, capítulo 18. In: Rouquayrol, M.Z. (org.). Epidemiologia e saúde. Rio de Janeiro: MEDSI, 1993.

13. Altman, D. Poder e comunidade: Respostas organizacionais e culturais à AIDS (História Social da AIDS, 5). Rio de Janeiro: Relume-Dumará, 1995.

14.Scheper-Hughest, N. An assay: AIDS and the social body. Social Science and Medicine. 39(7):991-1003, 1994. 